\title{
Os esqueletos humanos são dignos de proteção
}

\author{
Human skeletons are worth protecting
}

Vale la pena proteger los esqueletos humanos

Marta Stoffels ${ }^{1}$

\begin{abstract}
Resumo
Introdução: ante o avanço das ciências, cresce também o interesse nas coleções osteológicas já existentes e o desejo de construir novas, desde que a legislação nacional assim o permita. Proporcionalmente, aumentam as discussões relativas à bioética, instando as nações a revisitarem seus ordenamentos jurídicos visando à atualização do tema no que tange à proteção dos esqueletos humanos. Objetivo: suscita-se uma reflexão acerca do status jurídico dos esqueletos, da sua tutela nos âmbitos do Estado, no meio científico e acadêmico. Busca-se, também, fundamentos jurídicos que amparem os direitos à dignidade e à nacionalidade para os restos humanos esqueletizados. Metodologia: o método adotado é o da pesquisa bibliográfica com abordagem qualitativa. A técnica utilizada foi a análise textual descritiva acerca dos direitos atribuídos aos restos mortais. Resultados: a legislação vigente não impede que a doutrina majoritária considere, no âmbito do Direito, os ossos humanos como coisa. Essa condição enfraquece a proteção, fomenta o trânsito desenfreado e o comércio ilegal de ossos humanos. Conclusão: é imprescindível a inclusão, nos documentos regulatórios da matéria, um núcleo de proteção ampliado para os despojos humanos, cujo teor vise a garantir a dignidade que lhes é inerente. A normatização dos direitos aqui reivindicados inibirá questões envolvendo ossos humanos, que são dirimidas, atualmente, por um esforço exegético derivado dos direitos de personalidade, das leis do Direito Funerário ou pelas normas sanitárias locais, cujo amparo legal se restringe à imagem, à memória e à honra do indivíduo morto.
\end{abstract}

Palavras-chave: Restos mortais. Esqueleto. Ética. Legislação.

\begin{abstract}
Introduction: in the face of development of the sciences, there is also a growing interested in existing osteological collections and the desire to build new ones, provided that national legislation permits. Proportionally, discussions on bioethics increase, urging nations to revisit their legal systems with a view to updating the topic regarding the protection of human skeletons. Objective: to raise a reflection about the legal status of skeletons, their tutelage in the areas of the State, in the scientific and academic environment. We also look for legal bases that support the rights to dignity and nationality for the skeletonized human remains. Methodology: the method adopted is the bibliographic research with a qualitative approach. The technique used was the descriptive textual analysis of the rights attributed to the remains. Results: the current legislation does not prevent the majority doctrine from considering, within the scope of the law, human bones as a thing. This condition weakens protection, encourages unrestrained traffic and the illegal trade in human bones. Conclusion: it is essential to include an expanded protection nucleus for human spoils in the regulatory documents of the matter, whose content aims to guarantee the inherent dignity. The
\end{abstract}

\footnotetext{
${ }^{1}$ Doutoranda em Antropologia Forense pela Universidade de Coimbra, Portugal. E-mail: martinhastoffels@gmail.com
} 
regulation of the rights claimed here will inhibit issues involving human bones that are currently resolved by an exegetical effort derived from personality rights, the rules of Funerary Law or by local health rules, whose legal protection is restricted to the image, memory and the honor of the dead individual.

Keywords: Mortal remains. Skeleton. Ethic. Legislation.

\section{Resumen}

Introducción: en vista del avance de la ciencia, también existe un creciente interés en las colecciones osteológicas existentes y el deseo de construir otras nuevas, siempre que la legislación nacional lo permita. Proporcionalmente, las discusiones sobre bioética están aumentando, instando a las naciones a revisar sus sistemas legales com el fin de actualizar el tema com respecto a la protección de los esqueletos humanos. Objetivo: plantea una reflexión sobre el estado legal de los esqueletos, su tutela en las áreas del Estado, en el entorno científico y académico. También busca fundamentos legales que respalden los derechos a la dignidad y la nacionalidad de los restos óseos. Metodología: el método adoptado es el de la investigación bibliográfica con enfoque cualitativo. La técnica utilizada fue el análisis textual descriptivo sobre los derechos atribuidos a los restos. Resultados: la legislación actual no impide que la doctrina mayoritaria considere, dentro del alcance de la Ley, los huesos humanos como una cosa. Esta condición debilita la protección, fomenta el tráfico sin restricciones y el comercio ilegal de huesos humanos. Conclusión: es esencial incluir, en los documentos reglamentarios del asunto, un núcleo de protección ampliado para el botín humano, cuyo contenido tiene como objetivo garantizar la dignidad inherente. La regulación de los derechos reivindicados aquí inhibirá los problemas relacionados con los huesos humanos que actualmente se resuelven mediante un esfuerzo exegético derivado de los derechos de la personalidad, las leyes de Derecho Funerario o las normas locales de salud, cuya protección legal se limita a la imagen, la memoria y honor del individuo muerto.

Palabras clave: Restos mortales. Esqueleto. Ética. Legislación.

\section{Introdução}

Historicamente, é atribuído ao cadáver um valor moral, cultural e religioso. Após a morte de um indivíduo é deflagrado o respeito ao ius sepulchri, que é o direito de ser sepultado (ou cremado) e permanecer sepulto. Todavia, a legislação nacional de Portugal permite a exumação daqueles indivíduos que, após o transcurso do prazo legal estipulado para garantir a sua esqueletização, não se encontram em campa de caráter perpétuo.

Após a exumação, os despojos recolhidos e não reclamados pelos familiares do indivíduo identificado, bem como os restos mortais daqueles não identificados antes da inumação, são depositados no ossário local para subsequente cremação ou outro destino julgado mais adequado. Referida prática permite a continuidade dos sepultamentos, haja vista a falta de espaço nos cemitérios que atormenta os seus administradores.

Aborda-se o processo gerador de esqueletos humanos para pesquisa, atualmente vigente em Portugal, em virtude da solicitação oriunda do Canadá, em 2016, de doação de 
esqueletos de indivíduos portugueses não reclamados, objetivando a criação de uma coleção de referência para investigação científica e de ensino, uma vez que é vedada a exumação de cadáveres para esse fim naquele país. Aprovado o pedido pela Câmara Municipal de Lisboa $(\mathrm{CML})$ e, tornada pública a decisão, gerou a inconformidade dos cientistas locais uma vez que caracterizaria a exportação de esqueletos (1).

O ineditismo da situação expôs a lacuna legislativa existente em Portugal e, certamente, em muitos outros países afora. O insólito acontecimento ensejou a manifestação dos cientistas portugueses, por meio de carta enviada às autoridades decisoras, reivindicando legislação específica para a tutela de cadáveres humanos esqueletizados recentes, ante o seu caráter de patrimônio biológico nacional.

Nesse sentido, o objetivo do artigo é refletir acerca do status jurídico dos esqueletos, a ausência de regulamentação específica, e os posicionamentos acadêmicos e científicos sobre o tema.

\section{Metodologia}

Utilizou-se o método da pesquisa bibliográfica no intuito de identificar produções científicas, cujo teor abordasse eventuais direitos atribuídos a restos humanos esqueletizados, visando à fundamentação da sua relevância ímpar no âmbito dos direitos fundamentais, assim como na comunidade científica afim.

Foi utilizada uma abordagem qualitativa em livros do acervo da Biblioteca da Universidade de Coimbra; em artigo de jornal português; em artigos e sítios especializados, brasileiros e estrangeiros, disponíveis na Internet, a saber: Estudo Geral, repositório digital da produção científica da Universidade de Coimbra²; Procuradoria-Geral Distrital de Lisboa3; Espaço Jurídico ${ }^{4}$, Wiley Online Library ${ }^{5}$; Revista Âmbito Jurídico ${ }^{6}$; National Geografic ${ }^{7}$; Forensic Science Internationaß; ; Google Acadêmico ${ }^{9}$, entre outros.

Quanto à datação das publicações pesquisadas, cumpre ressaltar que, em razão de o tema deste artigo envolver direitos humanos fundamentais, não há que se delimitar a

\footnotetext{
2 https://estudogeral.sib.uc.pt

${ }^{3}$ http://www.pgdlisboa.pt/leis

${ }^{4} \mathrm{https}: / /$ portalperiodicos.unoesc.edu.br/espacojuridico

${ }^{5} \mathrm{https}: / /$ onlinelibrary.wiley.com/journal/

${ }^{6}$ https://ambitojuridico.com.br/

7 https://www.nationalgeographic.com

${ }^{8} \mathrm{https}: / / \mathrm{www}$.journals.elsevier.com/forensic-science-international

${ }^{9} \mathrm{https}: / /$ scholar.google.com
} 
atualidade da literatura clássica conceitual. Todavia, quanto aos posicionamentos de autores acerca de uma interpretação que viesse ao encontro da defesa de direitos que ora se busca, privilegiou-se estudos mais recentes.

As palavras-chave indexadas na busca da bibliografia foram: direito fúnebre; esqueletos humanos e direitos; direitos do de cujus; venda de ossos humanos; direito de personalidade do morto; direitos do cadáver; dignidade para o esqueleto humano; nacionalidade do cadáver. Destaca-se que a referida indexação culminou no desdobramento de vocábulos análogos na busca da matéria em questão, levando à ampliação desta pesquisa. Por derradeiro, a técnica utilizada foi a análise textual descritiva acerca dos direitos civis ampliados para os esqueletos humanos.

\section{Resultados e discussão}

Verificou-se a escassez de doutrina no enfrentamento direto da problemática que exsurge quando se trata de restos mortais humanos esqueletizados.

O entendimento majoritário considera o cadáver como uma coisa fora do comércio jurídico (2), porém não se encontra arrolado como tal no Regulamento das Coisas inserto no Código Civil português (3). Nessa esteira, Dias Ferreira aduz que "o cadáver, posto que não possa ser objecto de apropriação, visto achar-se fora do comércio (...) está indubitavelmente compreendido na categoria de coisas, por ser coisa tudo o que carece de personalidade” (3).

Alguns autores referem que o esqueleto, embora considerado como coisa, não é comerciável, consoante dispõe o artigo 20ํ, do Decreto-Lei nº 274/99 (regime jurídico da utilização de cadáveres para fins de ensino e investigação). Está impressa, na referida norma legal, a proteção do respeito devido ao cadáver, ante o sancionamento penal expresso para aquele que comercializar um cadáver, ou partes dele, ou peças, tecidos ou órgãos (4). Não obstante a vedação, Halling e Sedemann (5) verificaram que há crânios e material póscranial sendo comercializado no Yahoo! e até mesmo no Facebook. Especificamente no eBay, 354 crânios foram postados para venda nos Estados Unidos a um preço médio de abertura de $\$ 651,93(5)$.

De outra banda, encontram-se juristas e profissionais na área que se dedicam a descoisificar o cadáver, pois "a protecção do valor pessoal prolonga-se ainda depois da morte, no que respeita ao cadáver, pois este é tutelado como emanação da pessoa, e não como coisa" (6). Ainda, repudiam a qualificação do cadáver como coisa, sob os argumentos 
antropológicos e sociológicos. Eugénia Cunha, renomada cientista portuguesa, em nota ao jornal Público à época do episódio envolvendo a solicitação de doação de esqueletos para uma Universidade do Canadá, ressaltou: "os esqueletos humanos são restos de pessoas. Já não Ihes basta terem sido abandonados pela família?", referindo-se às ossadas exumadas nos cemitérios locais, em razão da expiração do prazo legal de inumação em sepulturas temporárias, e não reclamadas por familiares (1).

Desde os tempos mais remotos, o cadáver mereceu honras. "Atualmente, mesmo quem não professa nenhuma religião, denota para com o defunto uma consideração memorialista, consubstanciada em ritos. Deste modo, o cadáver, apesar de não ser portador de personalidade, não é coisa." (6). É um tertium genus.

O respeito ao corpo, à imagem e à memória do morto, direitos objetivos previstos no ordenamento jurídico, são de senso comum. No entanto, a controvérsia se instala em momento a posteriori, quando só restam os ossos do de cujus. Quais direitos pode-se invocar para algo que é considerado coisa, embora não comerciável?

Em resposta ao questionamento posto, busca-se, em especial, luzes na doutrina e no Direito português, haja vista a polêmica que deu azo à reflexão em tela. Para tanto, traz-se o entendimento de Capelo de Souza, citado na dissertação de doutoramento do jurista e professor André Pereira, in verbis:

[...] após a morte, o corpo humano transforma-se em cadáver, sem que isso deixe de constituir um bem de personalidade, na medida em que passa a ser um elemento básico da idéia também jurídica de pessoa falecida, relativamente à qual, e apesar da extinção da respetiva personalidade jurídica, subsistem direitos de personalidade nos termos do art. $71^{\circ}$ do Código Civil, nomeadamente no que concerne ao seu corpo sem vida. (7)

Porém, em leve objeção lógica ao pensamento de Capelo de Souza, o doutorando, à época, assim consignou:

[...] se bem entendemos, radicam os direitos subjetivos no conceito de personalidade humana juscivilisticamente tutelada, a qual - não se confundindo com a personalidade jurídica - não é um centro autónomo de imputação de direitos e deveres. Obriga, pois, a aceitar a tese da existência de direitos sem sujeito. Tese que, no caso do cadáver, pode levar a uma certa perplexidade, pois estes direitos - ao contrário dos "direitos do nascituro" nunca virão a ter sujeito ... para além de que se vão extinguindo pelo decurso do tempo e pelo apagamento da memória. Donde, talvez seja possível uma outra compreensão jurídica da devida tutela do cadáver e do respeito devido aos defuntos que não passe pela subjetivação e pela afirmação da existência de direitos subjetivos. (7) 
Ante os dois entendimentos lançados pelos ilustres pensadores, concorda-se com o primeiro quanto ao viés protetivo necessário para além do corpo morto, estendendo o amparo legal ao seu esqueleto por vias dos direitos de personalidade subsistentes. No entanto, percebe-se a objeção positivista do segundo quanto à despersonalização jurídica determinada pelo Código Civil Português (8) mediante o evento morte. Outrossim, André Pereira, parafraseando Paula Ribeiro de Faria, destaca a complexidade do tema, cujo tratamento doutrinal "ainda se encontra numa fase de polémica e incerteza: o estatuto jurídico do cadáver humano, a existência de direitos de personalidade post mortem e a proteção jurídica devida ao cadáver e à memória dos mortos" (7).

A problemática e a complexidade mencionadas, envolvendo os restos humanos esqueletizados recentes, perduram na atualidade. E, no intuito de inibir eventual banalização no tratamento dispensado aos esqueletos humanos, busca-se um amparo legal mais robusto para a sua tutela e manejo.

Nesse contexto, a condição sui generis que os ossos humanos atualmente detêm, juntamente com o término da personalidade jurídica imposta ao indivíduo morto pelo ordenamento legal português, contribuem para os impeditivos de uma proteção mais específica e efetiva perante o Estado.

\section{Questões de Direito e Ética}

A legislação portuguesa, nos termos dos Decretos-Lei ํo 411/1998 (9) e № 274/1999 (4), permitem que os restos mortais humanos esqueletizados sejam utilizados pela comunidade científica e pelas instituições para fins de pesquisa e de ensino.

No entanto, destaca-se que o cadáver humano esqueletizado não deve ser visto apenas como um material ou um instrumento, mas também como uma lição de vida por meio da morte, imprescindível para a formação sócio-cultural humana (10).

Transcorrido um determinado tempo após o sepultamento de um corpo, restam os seus ossos, despersonalizados juridicamente pelo Código Civil vigente e qualificados como coisa pela doutrina dominante. No entanto, na lavra de Samelo (6), os restos mortais não podem ser considerados como tal, embora destituídos de personalidade. Infere que o Direito atribui ao cadáver "importância suficiente para que o mesmo não seja catalogado como coisa no seu sentido mais estrito, mas como uma realidade sui generis". No entanto, complementa 
o autor, o Direito positivista ainda não ousou derrubar expressamente a fronteira que traçou entre Homem e coisa.

No momento em que o Poder Legislativo enfrentar a questão, mediante a participação dos especialistas do tema em voga, referida fronteira desapareceráqu. Sabe-se que a lacuna não deveria existir, em razão de o Direito consuetudinário, além de outros fatores sociais, impingirem vigilância ao Poder Legislativo quanto à atualidade das normas existentes ou quanto à necessidade de produzir outras. Quando há omissão, o Judiciário, se provocado, e no intuito de inibir eventual desordem social, assume e gera jurisprudência, que possuem status de fonte do Direito.

A doutrina de Barros e Pinheiro alinha quando refere com propriedade:

[...] cumpre não perder de vista que todo e qualquer instituto jurídico exige aprimoramento ao longo do tempo ou a criação de novos mecanismos em razão das demandas e das circunstâncias que lhe são propostas por meio das necessidades da gestão da vida cotidiana pela administração. O sinal da desatualização é uma forte evidência de que o direito legislado não se preocupou em avançar e modernizar a legislação vigente. (11)

Outro fator que pode vir a intrincar a normatização do tema é a Bioética. A manipulação de ossos humanos é um tema controverso e suscita debates acirrados sempre que necessária a delimitação das questões éticas envolvidas, sejam elas de cunho jurídico, filosófico ou religioso. Porém, a convergência de posicionamentos é imprescindível para a regulamentação da matéria. Para tanto, faz-se necessária a participação dos cientistas que possuem o conhecimento na área para auxiliar no processo legislativo respectivo.

Não obstante as divergências referidas, vigem os pilares da ética que norteiam a Antropologia Forense. Sua prática está fundada no respeito à história que os ossos humanos têm para contar. Aquele que manuseia restos mortais deve fazê-lo imbuído desse sentimento, sob pena de ferir os princípios basilares do exercício da especialidade.

Questões jurídicas (normas regulamentadoras) e éticas (valores morais que orientam o comportamento humano) devem confluir a fim de evitar constrangimentos, à semelhança da questão do Canadá, referida inicialmente, e que levou as autoridades legislativas portuguesas a consentir na remessa de esqueletos humanos, gerando a revolta da comunidade científica local. A contrariedade dos cientistas culminou em uma reflexão da Câmara sobre a decisão lançada, tanto que, pelo que se tem notícia, a remessa dos esqueletos portugueses para o exterior não ocorreu até a presente data. 
É notório que, em tempos remotos, a remessa de ossos humanos para outras nações acontecia, mas, atualmente, é controversa. Essa prática tende a ser reformulada, em razão de as circunstâncias temporais e o desenvolvimento sociocultural de uma coletividade assim requererem. Há um eixo de tolerabilidade, uma barra de proteção, uma linha divisória que delimita até que ponto algo, qualquer fato ou situação, é considerado tolerável por determinada sociedade. Como as coletividades humanas vão se modificando constantemente ao longo do tempo, o facto antes tolerável, futuramente pode se tornar intolerável e vice-versa (12).

Exemplifica-se a reformulação supramencionada com a criação, nos Estados Unidos, da Lei Federal, sob a sigla NAGPRA - Native American Grave Protection and Repatriation Act (Ato de Repatriação e Proteção dos Túmulos Nativo Americanos), editada por conta dos inúmeros litígios tramitados na Corte americana envolvendo comunidades indígenas tentando reaver, sob fundamentos religiosos, os restos esqueléticos de índios americanos escavados para estudo ou expostos em museus. Mencionada lei, embora regule exclusivamente o manejo do esqueleto do nativo americano, estabeleceu um precedente para o enfrentamento das preocupações éticas que se espalharam envolvendo os demais contextos de manipulação de ossos humanos $(13,14)$.

$\mathrm{Na}$ atualidade, impende a aplicação de uma exegese restritiva dos dispositivos legais que tendem a regular a matéria. Se assim não for, o diferencial humano deixa de existir levando os ossos em comento à uma vala comum e à sua exportação. Embora o Direito disponha de normas protetivas para o de cujus, o seu esqueleto não possui vinculação expressa nos textos legais, deixando-o, assim, à mercê da hermenêutica.

\section{Dignidade humana e nacionalidade}

Busca-se argumentos nos princípios que regem o Direito para estender, aos despojos humanos, os atributos de dignidade e de nacionalidade do indivíduo vivo. E, nessa esteira, almeja-se o entendimento dos legisladores de que o esqueleto deve ser considerado um material biológico nacional e não passível de doação para o estrangeiro.

Os fundamentos para se alcançar o pretendido encontram-se na abrangência das definições de dignidade e de nacionalidade, como direitos humanos fundamentais. O reconhecimento e a proteção desses direitos estão na base das Constituições democráticas modernas $(15,16)$. 
A dignidade lastreia os direitos humanos, os quais são naturais e inerentes a qualquer ser humano, reconhecidos por meio de instrumentos de direito internacional, como os tratados da Organização das Nações Unidas (ONU) e da Organização dos Estados Americanos (OEA).

Consoante o pensamento de Sarlet (17) "mesmo aquele que já perdeu a consciência da própria dignidade merece tê-la [a sua dignidade] considerada e respeitada". Sob esse viés, Oliveira aduz que

[...] uma pessoa, só pelo facto de pertencer ao género humano, já é detentora de dignidade. Esta é a qualidade ou atributo intrínseco a todos os seres humanos, decorrente da exata qualidade da sua humanidade, que os torna merecedores de igual estima e apreço por parte dos seus semelhantes, na medida em que, enquanto seres humanos ou pessoas, não têm preço. (18)

Por sua vez, a nacionalidade é um direito fundamental do ser humano positivado na Carta Magna dos Estados. É um vínculo jurídico entre o indivíduo e o Estado que fornece identidade e proteção diplomática, uma vez que são condições primeiras para a participação incondicional na sociedade.

Com base nos conceitos supramencionados, passa-se a tecer considerações no intuito de fundamentar a sua extensão aos restos humanos esqueletizados recentes. Tendo em vista que, além do princípio da dignidade humana ser um valor moral e espiritual inerente ao ser humano, é, também, considerado uma cláusula aberta. Nessa condição, inspira a exegese no caso concreto, permitindo uma interpretação alargada da expressão ser humano independentemente da sua condição fisiológica (vivo e morto). Ou seja, se há uma distinção pelo fato de ser humano, a dignidade e a nacionalidade não podem ser restringidas, abarcando, dessa forma, os seus despojos.

Segundo Peixoto (19), “a pessoa humana é uma identificação jurídica baseada em critérios biológicos e filosóficos, diferenciando os Homens dos demais seres vivos, de máquinas e objetos inanimados". Infere que, taxonomicamente, humano é o homo sapiens (homem sábio), sendo a dignidade um atributo essencial da pessoa humana pelo simples fato de alguém ser humano, se tornando automaticamente merecedor de respeito e proteção, não importando sua origem, raça, sexo, idade, estado civil ou condição sócioeconômica. Complementa o autor com a seguinte definição:

É um princípio fundamental incidente a todos os humanos desde a concepção no útero materno, não se vinculando e não dependendo da atribuição de 
personalidade jurídica ao titular, a qual normalmente ocorre em razão do nascimento com vida. É um critério unificador de todos os direitos fundamentais ao qual todos os direitos humanos e do homem se reportam, em maior ou menor grau, apesar de poder ser relativizado, na medida em que nenhum direito ou princípio se apresenta de forma absoluta. (19)

Kant (20), na Fundamentação da Metafísica dos Costumes, já defendia que as pessoas deveriam ser tratadas como um fim em si mesmas, e não como um meio (objetos). "Quando uma coisa tem preço, pode ser substituída por algo equivalente; por outro lado, a coisa que se acha acima de todo preço, e por isso não admite qualquer equivalência, compreende uma dignidade" (20).

$\mathrm{Na}$ esteira do pensamento de Kant, como os ossos humanos não têm preço (ao menos não deveriam ter) e o fato de não possuírem equivalente, então detêm dignidade. Outrossim, o exercício da hermenêutica permite entender que direitos inerentes ao ser humano abarcam o seu esqueleto, haja vista os ossos serem a remanescência material da sua existência, não devendo ser cabível a sua dissociação.

Uma vez ser humano, incluídos os seus restos mortais, há de se reivindicar a proteção diplomática por parte do Estado. Os pressupostos para tanto estão atendidos em razão de estabelecido o vínculo estatal no momento da atribuição de uma identidade, sem prejuízo àqueles cuja identidade se perdeu em razão do seu contexto de vida no momento da sua inumação (indigência).

Exemplifica-se a relevância atribuída à nacionalidade de um povo ante a movimentação do Estado em busca dos seus soldados, cujos corpos se encontram depositados nas valas comuns das zonas de conflito. Outra situação a ser lembrada é a do faraó egípcio Ramsés II, embora sui generis, exalta o respeito dos despojos mortais, quando o seu esqueleto (mumificado) foi enviado do Egito à França, em 1976, para tratamento de fungos, mediante a confecção prévia de um passaporte atestando a sua nacionalidade (21).

Não importa se a existência de um indivíduo foi notória, mediana ou insignificante, o seu esqueleto é a única remanescência material da sua existência. Visível deve ser a igualdade de condições no que tange à importância, ao respeito, à dignidade atribuída aos seus restos mortais.

Um corpo decomposto é detentor de direitos. Cabe mencionar a exegese da Ministra do Superior Tribunal Federal (STF) do Brasil, Cármen Lúcia Antunes Rocha, quando assenta o seguinte entendimento: 
Não há direito para a morte, nem um direito dos mortos. O que se protege quando se fala em morte ou na segurança do corpo para depois da morte é uma projeção do direito à vida, da proteção da dignidade e da integridade, mesmo quando não há mais a resposta material do viver. (22)

Extrai-se da manifestação da Ministra que a ideia de dignidade veio para atingir não só o mundo das pessoas fisicamente vivas, mas também aquelas que já morreram, mediante a preservação da imagem, da intimidade e da privacidade do corpo do morto, alcançando, salvo melhor juízo, o seu esqueleto, especialmente quando destinado para estudos e pesquisas científicas.

Embora o direito da personalidade jurídica cesse com a morte da pessoa natural, a tutela e o manuseio dos seus restos esqueletizados para fins científicos e de ensino em nada prejudica a preservação dos direitos ora invocados, desde que aconteça de forma a não macular a dignidade e a nacionalidade desses indivíduos.

\section{Esqueletos não identificados e esqueletos identificados e não reclamados}

No que tange aos restos mortais não identificados e exumados devido ao término do prazo legal de ocupação da campa, são pessoas que, no momento da sua morte e subsequente inumação, tiveram impossibilitada a sua identificação em razão do contexto de vida em que se encontravam, geralmente na indigência. Para essa situação, cabe referir o teor da Apelação Cível no 70077059210, Décima Sexta Câmara Cível, Tribunal de Justiça do RS/Brasil, julgado em 26 de abril de 2018, que refere:

Não se pode perder de vista que indigentes, em sua maioria, são indivíduos
que perderam qualquer contato com parentes próximos, o que inviabiliza a
sua busca por auxílio familiar ou a própria identificação destes, a ser
realizada, como pretendido, por entidades assistenciais governamentais. Se
a própria identificação e estabelecimento de contato pessoal com os
familiares já é tarefa árdua (se não impossível de ser efetivada) quando do
sepultamento, tal empreitada certamente beirará ao impossível quando da
remoção de seus restos mortais, diligência a ser realizada, de regra, alguns
anos após o falecimento, quando os tênues laços mantidos em vida
possivelmente se desfizeram por completo. (23)

Relativamente aos esqueletos identificados, são aqueles que, igualmente exumados em decorrência de expiração do prazo de inumação, não foram reclamados pelas famílias respectivas. 
As condições de ambos os tipos de restos mortais esqueletizados ora em tela, têm como característica principal o abandono, os que os torna especialmente merecedores de todo o empenho do Estado a fim de preservar a sua dignidade e a sua nacionalidade.

\section{Conclusão}

Fundamenta-se, sob o viés filosófico e jurídico e fulcro nos direitos fundamentais, o entendimento de que os restos mortais de um indivíduo, embora destituídos de personalidade jurídica, remanescem com direito à dignidade e à nacionalidade, em razão da sua relevância como material biológico nacional.

Conforme referido anteriormente, a sociedade está em constante evolução, incluída a comunidade científica. No entanto, a legislação, por vezes, não acompanha os novos costumes ou necessidades de uma nação. Essa situação aplica-se à falta de regulamentação específica acerca de esqueletos humanos e aos limites da sua tutela no âmbito científico e de ensino, incluídas as questões éticas controvertidas.

Nesse passo, Ubelaker e Grant (24), sobre o uso de restos humanos e outros materiais para os fins acima citados, referem que "deve-se fazê-lo com respeito pelos sentimentos de dignidade humana de todos os povos". Há décadas, os casos envolvendo repatriamento de restos mortais de índios americanos, por questões religiosas, têm gerados decisões conflituosas por questões complexas como religião, ética, ciência e política. Antropólogos, biólogos, enfim, todos os envolvidos com despojos humanos esqueletizados foram instados a rever os objetivos de suas pesquisas e a avaliar a importância das análises e curadoria.

Portanto, em razão de todo o exposto, embora a legislação portuguesa permita que determinados restos mortais possam ser utilizados para fins de estudos científicos, defendese que essa prática deve ocorrer no âmbito do território português. Entende-se que a anuência jurídica para tal fim não pode ser estendida, sob pena de macular direitos fundamentais celebrados universalmente.

Igualmente, defende-se a impossibilidade de exportar ossos humanos, em observância ao dever de tutela do Estado para com o seu material biológico nacional, incluída a preservação dos direitos fundamentais (dignidade e nacionalidade) que revestem os restos mortais dos seus cidadãos. Portanto, a sua utilização para fins de investigação científica deve se restringir à circunscrição da nação à qual pertencem, sem óbice à eventual investigação científica que outros países queiram promover em solo português. 
Por derradeiro, cabe ao Poder Legislativo de Portugal, e de outros países que se encontram em situação similar, regulamentar a matéria, de forma pontual, ouvidas as representações científicas, religiosas e outras vertentes envolvidas. Espera-se que a normatização se dê no sentido da permanência dos esqueletos humanos em solo pátrio. Todavia, caso regulado de forma diversa, ad cautelum, há de contemplar a definição dos limites da tutela do Estado, as regras de sua saída para outro país, e, em especial, a garantia de manutenção do sigilo dos dados identificadores em solo estrangeiro.

\section{Referências}

1. Firmino T. Cientistas portugueses unem-se contra exportação de esqueletos. Público. 06 dez 2016. Disponível em:

https://www.publico.pt/pesquisa?query=exportação+de++esqueletos. [Acesso em 12.abr.2019].

2. Horster HA. Parte Geral do Código Civil Português - Teoria Geral do Direito Civil. Coimbra; Almedina, 2000.

3. Ferreira D. Código Civil Português Anotado. 2ª edição. vol. I. Coimbra: 1894.

4. Portugal. Decreto-Lei n.. 274/99, 22 de julho de 1999. Regula a dissecação de cadáveres. Regula a dissecação de cadáveres e extracção de peças, tecidos ou órgãos para fins de ensino e de investigação científica. Disponível em:

http://www.pgdlisboa.pt/leis/lei_mostra_articulado.php?nid=239\&tabela=leis\&ficha=1\&pagin $\mathrm{a}=1 \&$ so_miolo=\& [Acesso em 04.abr.2019].

5. Halling CL, Seidermann RM. They Sell Skulls Online?! A Review of Internet Sales of Human Skulls on eBay and the Laws in Place to Restrict Sales. Journal Forensic Sciences. (04 jul 2016); 61(5):1322-6. DOI: 10.1111/1556-4029.13147.

6. Samelo NTCR. Aspectos relativos à tutela post-mortem da Personalidade Humana no Direito Civil: uma abordagem juscivilística do problema dos cemitérios [Dissertação]. Coimbra: Mestrado na Área de Especialização em Ciências Jurídico-Forenses, Faculdade de Direito da Universidade de Coimbra; 2015. Disponível em: http://hdl.handle.net/10316/31346. [Acesso em 20.mai.2019].

7. Pereira AGD. Direito dos Pacientes e Responsabilidade Médica [Tese]. Coimbra: Doutoramento em Ciências Jurídico-Civilísticas, Faculdade de Direito da Universidade de Coimbra; 2012. Disponível em:

https://estudogeral.sib.uc.pt/bitstream/10316/31524/1/Direitos\%20dos\%20pacientes\%20e\% 20responsabilidade\%20médica.pdf

8. Portugal. Decreto-Lei n.. 47344/66, 25 de novembro de 1966. Código Civil. Aprova o Código Civil e regula a sua aplicação - Revoga, a partir da data da entrada em vigor do novo Código Civil, toda a legislação civil relativa às matérias que o mesmo abrange. 
Disponível em:

http://www.pgdlisboa.pt/leis/lei_mostra_articulado.php?nid=775\&tabela=leis\&so_miolo= [Acesso em 04.abr.2019]

9. Portugal. Decreto-Lei $n . .411 / 98,30$ de dezembro de 1998. Inumação e trasladação de cadáveres. Estabelece o regime jurídico da remoção, transporte, inumação, exumação, trasladação e cremação de cadáveres, bem como de alguns desses actos relativos a ossadas, cinzas, fetos mortos e peças anatómicas, e ainda da mudança de localização de um cemitério. Disponível em:

http://www.pgdlisboa.pt/leis/lei_mostra_articulado.php?nid=246\&tabela=leis\&so_miolo= [Acesso em 05.abr.2019].

10. Chagas JS. Cadáver Desconhecido - Importância histórica e acadêmica para o estudo da anatomia humana [Dissertação]. São Paulo: Mestrado em Ciências, Escola Paulista de Medicina, Universidade Federal de São Paulo (UNIFESP); 2001. Disponível em: http://repositorio.unifesp.br/handle/11600/17186 [Acesso em 12.abr.2019].

11. Barros MALL, Pinheiro GC. A proteção ampliativa dos direitos fundamentais no Judiciário: o caso do direito funerário. Espaço Jurídico Journal of Law [EJJL]. (26.abr.2018), 19 (1):181-200. DOI: https://doi.org/10.18593/ejjl.v19i1.11040

12. Motta AFMR. A dignidade da pessoa humana e sua definição. Âmbito Jurídico. 01.dez.2013; XVI (119): [15]. Disponível em: http://www.ambitojuridico.com.br/site/?n_link=revista_artigos_leitura\&artigo_id=14054>[Acesso em 05.mai.2019].

13. Langley NR, Tersigni-Tarrant MTA. Forensic Anthropology - A Comprehensive Introduction. 2 $2^{\mathrm{a}}$ ed. London: CRC Press; 2017.

14. Landau PM, Steele GD. Why Anthropologists Study Human Remains. American Indian Quarterly. (Spring, 1996), 20 (2), (Special Issue: Repatriation: An Interdisciplinary Dialogue): 209-228. DOI:10.2307/1185701.

15. Bobbio N. A Era dos Direitos. Rio de Janeiro: Elsevier; 2004

16. Portugal. Constituição da República Portuguesa. VII revisão constitucional 2005, 10 de abril de 1976. Decreto de aprovação da Constituição - Diário da República n.ํ 86/1976, Série I. Disponível em: https://dre.pt/web/guest/legislacao-consolidada//lc/34520775/view?q=constituicão+da+republica+portuguesa > [Acesso em 20.mar.2019].

17. Sarlet IW. Dignidade da Pessoa Humana e Direitos Fundamentais na Constituição Federal de 1988. Porto Alegre: Livraria do Advogado, 2001.

18. Oliveira FARS. Breves considerações a respeito do princípio da dignidade da pessoa humana [Dissertação]. Porto: Mestrado em Direito; Ciências Jurídico-Filosóficas da Faculdade do Porto; 2013. Disponível em: https://hdl.handle.net/10216/68997> [Acesso em 02.jun.2019]. 
19. Peixoto YHM. O princípio da dignidade da pessoa humana e as políticas públicas de saneamento básico no Estado de Goiás [Dissertação]. Goiás: Mestrado na Pontifícia Universidade Católica de Goiás - Programa de Pós-Graduação em Direito, Relações Internacionais e Desenvolvimento; 2016. Disponível em: tede2.pucgoias.edu.br:8080/.../YARA\%20HILÁRIO\%20MEDEIROS\%20PEIXOTO.pdf [Acesso em 14.mai.2019].

20. Kant I. Fundamentação da Metafísica dos Costumes e Outros Escritos. Lisboa: Edições 70, 2014.

21. Gardiner K. Mummy mugshots and other strange passport facts. National Geographic. 26.out.2018. Disponível em: https://www.nationalgeographic.com/travel/features/weirdpassports-history/ [Acesso em 10.mai.2019].

22. Bravo T. Direito Funerário - Cemitérios. JusBrasil. 2014.Disponível em: http://thibravo.jusbrasil.com.br/artigos/169156416/direito-funerariocemiterios [Acesso em 25.abr.2019].

23. Brasil. Tribunal de Justiça do Rio Grande do Sul. Apelação Cível № 70077059210. Apelante: Cemitério Parque Padre Pio Ltda. Apelado: Município de Bento Gonçalves. Relatora: Desa Deborah Coleto Assumpção de Moraes. Porto Alegre, 07 mai 2018.

24. Ubelaker DH, Grant LG. Human skeletal remains: Preservation or reburial. American Journal of Physical Anthropology. (1989), 32 (Issue S10): 249-287. DOI: 10.1002/ajpa.1330320511.

Como citar este artigo: 